\title{
OS DESAFIOS DA GESTÃO ESCOLAR
}

\section{ARTIGO ORIGINAL}

CORREIA, Regina Almeida Soares ${ }^{1}$

CORREIA, Regina Almeida Soares. Os desafios da Gestão Escolar. Revista Científica Multidisciplinar Núcleo do Conhecimento. Ano 04, Ed. 07, Vol. 07, pp. 31 39. Julho de 2019. ISSN: 2448-0959

\section{RESUMO}

Este trabalho tem por objetivo conhecer a dimensão política que vem sendo adotada em redes de ensino, analisar as estratégias utilizadas como ferramenta estadista dentro do setor educacional e refletir sobre o papel do gestor escolar frente ao direcionamento da educação, um papel imprescindível para o sucesso do ensino. Os Desafios Da Gestão Escolar justificam-se pela necessidade de verificar quais práticas estão sendo utilizadas e o que pode ser mudado para melhorar e ampliar a qualidade do ensino, para assim, enfrentar a competitividade e as dificuldades que existem para oferecer um ensino de qualidade com qualificação profissional do corpo docente, buscando à participação das famílias no âmbito escolar e amenizando a desistência e distorção idade-série. Este artigo tem como objetivo articular a teoria com a busca de solução de problemas da área de gestão educacional e práticas pedagógicas presentes no dia a dia dos administradores educacionais com reflexo direto no corpo escolar. Foi realizado pesquisa bibliográfica considerando as contribuições de autores

1 Pós Graduada em Gestão Educacional e Práticas Pedagógicas pela Faculdade Única De Ipatinga - FUNIP; Graduada em Pedagogia pelo Centro Universitário da Grande Dourados - UNIGRAN; Graduada em Licenciatura em Música pela Universidade Metropolitana de Santos - UNIMES e cursando Pós Graduação em Educação Especial e Inclusiva com Ênfase em Deficiência Intelectual e Múltipla pela Universidade Candido Mendes - UCAM. 
e pesquisadores como LÜCK (2014), PASCHOALINO (2017), GELATTI e MARQUEZAN (2013), entre outros. Para atingir o objetivo proposto, utilizou-se o método comparativo de abordagem qualitativa e caráter descritivo. Concluiu-se a importância de ter uma gestão de excelência adotando uma postura de parceria em busca de solução e não apenas de cobranças para obter resultados, uma gestão democrática com abordagem gerencial pautada na participação ativa da comunidade escolar e nos processos decisórios da instituição.

Palavras Chave: Gestão Escolar, desafios, práticas pedagógicas.

\section{INTRODUÇÃO}

O presente trabalho tem como proposta refletir acerca das práticas de gestão escolar e suas relações com as práticas pedagógicas numa perspectiva que reúne os procedimentos comuns da administração de uma instituição escolar, tais como olhar para a comunidade, para o aluno e para a situação educacional do qual estão inseridos.

Nesta perspectiva, construiu-se questões que nortearam este trabalho:

Quais as dificuldades e limitações que um bom gestor escolar precisa superar?

A qualidade do ensino é reflexo da excelência de uma gestão escolar construída e planejada sobre um papel social humanizado?

Desta forma um gestor necessita analisar à sua aplicação de práticas administrativas de maneira crítica e rigorosa a fim de avaliar a instituição e de propor mudanças para melhorar sua qualidade. A Educação é mais que um mero produto é um compromisso filosófico e um ideal humanitário, vai além da finalidade de só cumprir as exigências burocráticas e honrar os compromissos financeiros é necessário organização e administração do espaço escolar; gestão dos recursos físicos, materiais e humanos; cumprimento das leis, diretrizes, estatutos e, organização e planejamento do sistema 
educacional, trabalhando na elaboração e na execução de projetos pedagógicos para garantir melhoria na qualidade educacional. PASCHOALINO, enfatiza que:

O discurso de qualidade nas escolas passou a ser proferido nos mais diversos espaços da sociedade. Essa meta de qualidade está posta como um desafio para os gestores escolares, que passaram a ser cobrados pelo desempenho dos alunos. A qualidade escolar como meta de trabalho gestor, não é apenas uma especialidade brasileira referendada pelos textos legais, mas constitui um desafio constante independentemente do país. (PASCHOALINO, 2017, pag. 55).

Neste contexto, o objetivo primordial deste estudo é, pois, investigar quais são os desafios da gestão educacional frente às interações que ocorrem na escola, essencialmente entre gestão e corpo escolar, identificando quais são as ações que fazem o diferencial frente as atribuições dos gestores, segundo os princípios da gestão democrática para uma educação de qualidade.

O gestor têm um desafio próprio, tudo o que acontece com a instituição é, de certa forma, sua responsabilidade, seu papel é orientar desde a atuação do corpo docente garantindo que sejam devidamente capacitados e trabalhem motivados, até a Secretaria, departamento financeiro, almoxarifado, limpeza e conservação, alimentação, monitoria, inspecionamento, portaria, ou seja toda a instituição está sob seu comando, ele é o principal porta-voz da organização e deve zelar pelo interesse de todos os envolvidos. Com base no que foi descrito acima e considerando a afirmação da professora (PASCHOALINO, 2017, pag. 314), ressalta que: [...] Nessa lógica, o gestor precisa ter um conhecimento global da realidade educacional para agir diante das demandas no cotidiano do seu trabalho.

A pesquisa visou compreender o modelo educacional, as formas próprias de organização, os paradigmas da gestão educacional e suas contribuições para o sucesso do Aprendizado. Dos documentos analisados considerou-se o papel do gestor no sucesso da escola, as ações executadas pelas instituições para garantirem 
a qualidade da educação e os desafios que o gestor educacional enfrenta para desempenhar uma gestão democrática e participativa.

Para desenvolvimento deste estudo foi utilizado à pesquisa bibliográfica de materiais publicados em livros, artigos, dissertações e teses que nortearam o objeto da pesquisa e o direcionamento do estudo, fundamentado nas ideias e concepções de autores como: CAVALCANTI (2018), PEREIRA e VIEIRA (2013), NEVES (2018), LOPES (2010).

\section{JUSTIFICATIVA}

A qualidade de ensino não depende apenas de bons recursos financeiro, o gestor deve assegurar que a equipe coloque em prática projetos pedagógicos que impactam positivamente esse entorno, afinal é com excelência pedagógica que se forma cidadãos íntegros, capazes de analisar, criticar e transformar a sociedade em que vivem, pois, segundo Lück (2014) o que define princípios de capacitação e desenvolvimento de competência de Liderança para uma equipe de gestão, resumese na afirmação:

Conheça a natureza do seu trabalho, compreenda os seus múltiplos desdobramentos e desenvolva o domínio dos fundamentos, métodos e técnicas necessários para essa atuação profissional.

Conheça a escola como uma organização social e compreenda a sua cultura, em seus desdobramentos, possibilidades e limitações a serem superadas.

Desenvolva habilidades de comunicação, relacionamento interpessoal, gestão de conflitos e desenvolvimento de equipe. (LÜCK, 2014, pag. 130 e 131).

A educação necessita de uma gestão democrática, com colaborados que interagem uns com os outros, tendo toda a equipe de coordenadores, professores, orientadores, 
funcionários e famílias que compõem a comunidade escolar envolvidos na gestão, inspirando uma visão de futuro, baseado nas demandas da sua comunidade escolar, isto garante um senso de propósito de estarem participando em um projeto transformador.

A contribuição da equipe escolar é significativa, portanto é preciso tomar atitudes que realmente demonstrem aceitação e incentivo, atribuindo os resultados aos autores da solução para que outros membros da equipe também se manifeste sentindo-se estimulados a manifestarem as suas opiniões e a contribuírem para a solução de problemas.

O interesse por essa problemática surgiu em decorrência da atividade profissional e dificuldades quanto as práticas pedagógicas, o que resulta no comprometimento do envolvimento e participação visando a qualidade do ensino/aprendizagem, em função de uma gestão democrática e eficiente.

\section{OBJETIVOS}

Todo gestor educacional precisa se importar e trabalhar para alcançar resultados melhores, para auferir tal propósito é necessário promover o aperfeiçoamento constante da equipe e participar da construção desta, acreditando no potencial do profissional, motivando-o a implementar melhorias constantemente, aprender novos métodos de ensino, novas abordagens em prol das dificuldades dos alunos, novas aplicações de tecnologia na realidade escolar, mostrando que também está disposto a assimilar novos modelos de gestão e a adotar procedimentos para tornar-se menos burocrático e mais eficiente.

Especificamente: Orientar, acompanhar e apoiar o corpo docente e a equipe pedagógica quanto ao exercício das suas tarefas com o objetivo de alcançar melhores resultados; Acompanhar e conhecer as diversas metodologias e abordagens didáticas afim de orientar o corpo docente a utilizá-las para melhorar a qualidade do ensino; Observar o trabalho pedagógico, analisar os resultados, conduzir e implantar melhorias para tornar o processo de ensino e de aprendizagem cada vez mais eficaz;

Disponível em: https://www.nucleodoconhecimento.com.br/educacao/os-desafios-da-gestao- 
Reiniciar o ciclo de avaliação e aperfeiçoamento, ajudando-os a implantar melhorias que elevem o desempenho da instituição; Buscar continuamente os melhores métodos de ensino e aprendizagem para os educandos, criando um ambiente propício e estruturado para que os alunos absorvam todo o conhecimento dispensado; Refletir a diversidade presente entre os atores que compõem a comunidade escolar, valorizando as diferenças no comprometimento com o direito universal à educação.

\section{DESENVOLVIMENTO}

O bom gestor escolar consegue estabelecer uma relação de parceria com a sua equipe. A tomada de decisão é uma estratégia importantíssima para obter comprometimento e colaboração, buscando atender às necessidades de todos os setores da escola de forma integrativa, oferecendo suporte para os envolvidos na formação dos alunos. Democratizar o Processo de tomada de decisões, seja pela otimização de processos ou pela formação continuada é a tônica importante para unir a equipe em torno de um projeto de excelência. Com base no exposto, a professora Paschoalino, salienta que:

[...] a gestão escolar tem preconizado que a posição de liderança educacional e a expectativa de democracia passariam a ser responsabilizada pela qualidade do ensino ofertado. As premissas de atuação dos gestores escolares, recomendadas pelos valores normativos, foram alicerçadas sob os princípios de liderança, de participação coletiva, de eficiência, de competência e de qualidade. (PASCHOALINO, 2017, pag. 117).

Adotar uma postura de parceria em busca de solução, e não apenas de cobranças para obter resultados, e assim, será possível construir uma equipe unida e eficiente. Se o trabalho pedagógico não tem o resultado que o gestor deseja, possivelmente não é porque o corpo docente não está interessado em alcançar a excelência, porque todo educador deseja trabalhar em uma instituição que reconheça sua qualidade e sua 
capacidade de avançar, um fator que comumente impede uma instituição de alcançar o nível de excelência pode sim, ser a incapacidade que o gestor tem de reconhecer e aplaudir as atitudes de seus colaboradores quando eles acertam ou ainda, quando eles tomam uma decisão acertadíssima para resolver um nível de complexidade.

Sem uma gestão pedagógica de qualidade, a escola não tem o que oferecer à sociedade. Segundo Gelatti e Marquezan, em seu Trabalho de Conclusão de Curso "Contribuições Da Gestão Escolar Para A Qualidade Da Educação", preconizam que:

[...] para se conquistar a tão almejada qualidade na educação, faz-se necessário que a equipe escolar atue de forma a promover uma gestão escolar democrática, destacando o importante papel da equipe diretiva da escola na condução deste processo. Uma escola que promove uma gestão democrática, participativa e com o comprometimento e envolvimento de todos os responsáveis pelo processo de aprendizagem, terá como consequência deste trabalho e esforço a qualidade da educação e o sucesso da escola. (GELLATTI E MARQUEZAN, 2013, pág. 61).

Ter uma gestão unida, capaz de utilizar as suas atribuições e as suas habilidades para alcançar esse objetivo comum e avaliar periodicamente os resultados obtidos em cada ação implementando mudanças qualitativas no processo organizativo, promovendo a superação no desenvolvimento dos processos educacionais, mediante gestão participativa e construtiva, favorecendo o desenvolvimento de competências e habilidades dos educandos afim de torná-los sujeitos reflexivos.

O gestor educacional deve ter atuação de líder, precisa ter motivação, dinamismo, responsabilidade, criatividade e gerar um clima de confiança, transformação, atitudes e estímulos para com os integrantes do corpo docente para que sigam em direção a uma escola reflexiva, autônoma, participativa visando potencializar os ideais educacionais, incentivando a participação crítica e transformando a escola num 
verdadeiro espaço de construção do conhecimento. Dentro desta perspectiva, Lück, (2014, p. 96, apud LÜCK, 2006a) enfatiza que:

A gestão escolar e a gestão pedagógica devem receber a devida atenção de modo à evitar que uma delas fique defasada, prejudicando a qualidade e o sucesso da instituição. A gestão pedagógica é um pilar da gestão educacional e o gestor que almeja um resultado qualitativo no trabalho pedagógico deve interagir, cooperar, comunicar e motivar sua equipe, a fim de diversificar e potencializar as relações interpessoais mediante situações cotidianas do convívio escolar, ressignificando novas práticas num contexto sócio histórico comprometido com a preparação para o futuro adquirindo conhecimentos e desenvolvendo competências que forme educandos aptos a marcar uma presença na sociedade do amanhã.(LÜCK, 2014, pag. 96).

A qualidade na gestão nos faz entender que quando um gestor assume o papel de mediador e articulador das propostas pedagógicas, buscando solidificar a participação coletiva através das discussões, reflexões, ações e avaliações constantes do seu trabalho de gestão, favorece o comprometimento da escola em fortalecer nos seus colaboradores um hábito democrático, assegurando companheirismo e a compreensão de que um trabalho em parceria garante melhorias generalizada que, por consequência, traz melhoras nos indicadores e diminuição do abandono e da reprovação.

\section{CONCLUSÃO}

Com a pesquisa bibliográfica, conclui-se que as dificuldades e limitações que um bom gestor escolar precisa superar, os desafios enfrentados frente à gestão escolar e para que o ensino de qualidade seja o reflexo da excelência de uma gestão escolar construída e planejada sobre um papel social humanizado, questões temáticas levantadas neste artigo, é necessário que o Gestor Escolar seja democrático, participativo, atualizado, ativo, responsável, visionário, motivador, tenha 
conhecimento das problemáticas da escola e liderança, logo com essas qualidades cumprirá o papel do diretor escolar e conduzirá a instituição ao sucesso. Para fundamentar esta conclusão, Filippin, 2013 em Monografia de Conclusão de Curso, intitulada: "Gestão Escolar Democrática: Dificuldades, Especificidades e possibilidades a partir da Revista Nova Escola", salienta que:

Desafio é uma palavra ligada a gestão escolar. O desafio atual é uma escola de qualidade, ou seja, a gestão é elemento determinante para um trabalho significativo a ser realizado na escola, com os professores, funcionários, alunos, pais e comunidade escolar.

Toda organização que abrange a gestão escolar perpassa pelos aspectos administrativos, físicos, pedagógicos e sociais, não apenas por uma esfera particular e individual. E estes aspectos precisam estar bem articulados para contribuir com uma escola de qualidade, para que a mesma possa atingir suas metas e objetivos. (FILIPPIN, 2013, pág. 11).

O artigo "O Papel Do Diretor Escolar No Sucesso Da Instituição", publicado na ESCOLAWEB LTDA, tem em seu texto que "O diretor exerce uma importante função no cotidiano escolar":

Seu papel corresponde ao de um líder, podendo influenciar a todos de maneira positiva ou negativa. Ele é de extrema importância para o dia a dia de uma instituição escolar e deve desenvolver suas habilidades constantemente, com o objetivo de favorecer a qualidade da educação oferecida pela escola, assim como o estímulo às equipes que nela trabalham e a integração entre todos, inclusive pais e responsáveis. (ESCOLAWEB LTDA. 2017, pág. 1).

De acordo com Lopes, (2010,), em seu artigo "Os Principais Desafios Do Gestor Democrático Na Atualidade", apud Carvalho, 2015. Pág. 92. 
O Diretor-Gestor é um líder democrático, que trabalha, coopera, sugere que sabe fazer, participando das tarefas, que diz "nós" para avaliação dos efeitos positivos ou negativos da instituição. Este é o líder da organização que aprende e que assume responsabilidades, possibilita autonomia, que interage, participa e coordena à busca de soluções e construções. Visa um grupo motivado, cooperativo e que tenha vontade de crescer. Enfim, um líder leal, que seja o elo das ligações interpessoais com parceria, que não impõe sua verdade, mas que constrói verdades com o grupo e tem o respaldo da comunidade escolar, fazendo-a participar ativamente, trazendo-a cada vez mais para dentro da Escola e buscando estreitar sempre os laços de parceria e cumplicidade. (CARVALHO, 2015, pág. 92).

O equilíbrio de uma gestão escolar é essencial para que a instituição alcance os seus objetivos, as relações que se entrelaçam entre educação, gestão e democracia tornam-se essencial no âmbito educacional. A consolidação de uma gestão escolar de caráter participativo implica a democratização da escola efetivada por meio da participação dos sujeitos sociais nos processos de decisão, de escolhas coletivas, vivências, aprendizagens e construção de projetos, uma estruturação coletiva que bem alinhada, promove o sucesso da instituição e um impacto positivo na sociedade.

\section{REFERÊNCIAS}

CARVALHO, Luís Cláudio Rodrigues de. A Apropriação de Resultados do PROEB e as Estratégias Utilizadas por Duas Escolas de Ensino Fundamental da Rede Estadual de Ensino de Juiz de Fora. Dissertação de Mestrado. Disponível em: https://repositorio.ufjf.br/jspui/bitstream/ufjf/2264/1/luisclaudiorodriguescarvalho.pdf. Acesso em: 25 de set. de 2018. Às $20 \mathrm{~h}$ e $50 \mathrm{~min}$.

CAVALCANTI, Lilian. Os desafios da Gestão Escolar. Direcional Escolas - A Revista do Gestor Escolar. Disponível em: https://direcionalescolas.com.br/osdesafios-da-gestao-escolar/. Acesso em: 02 de dez. de 2018. Às: 12h e 50min. 
EscolaWeb. Gestão escolar e gestão pedagógica: diferentes e complementares! Blog de Materiais Educativos. Disponível em: https://www.escolaweb.com.br/blog/gestao-escolar-e-gestao-pedagogica-diferentese-complementares/. Acesso em: 01 de dez. de 2018.

ESCOLAWEB LTDA. O Papel Do Diretor Escolar No Sucesso Da Instituição. Ano de Publicação, 2017. Disponível em: https://www.escolaweb.com.br/blog/gestaoescolar/o-papel-do-diretor-escolar-no-sucesso-da-instituicao/. Acesso em: 18 de nov. de 2018. Às: 20h.

FILIPPIN, Tagiane Michele. Gestão Escolar Democrática: Dificuldades, Especificidades E Possibilidades A Partir Da Revista Nova Escola. UFSM - 2013. Disponível

em: https://repositorio.ufsm.br/bitstream/handle/1/512/Filippin_Tagiane_Michele.pdf?sequ ence $=1$. Acesso em: 15 de nov. de 2018. Às: $14 \mathrm{~h}$ e $20 \mathrm{~min}$.

GELATTI e MARQUEZAN. Contribuições Da Gestão Escolar Para A Qualidade Da Educação. Universidade Federal de Santa Maria, Brasil. Disponível em: https://periodicos.ufsm.br/regae/article/download/10825/pdf. Acesso em: 25 de out. de 2018. Às: $15 \mathrm{~h}$ e $20 \mathrm{~min}$.

LOPES, Maria Immacolata Vassallo. Contribuições do Modelo Metodológico à Pesquisa de Comunicação. Disponível em: https://edisciplinas.usp.br/mod/resource/view.php?id=1639179. Acesso em: 27 de out. de 2018. Às: $18 \mathrm{~h}$ e $20 \mathrm{~min}$.

LOPES, Tatiana Raquel Wilde. Os Principais Desafios do Gestor Democrático na Atualidade. Brasil Escola - Meu Artigo. Disponível em: https://meuartigo.brasilescola.uol.com.br/administracao/os-principais-desafiosgestor-democratico-na-atualidade.htm. Acesso em: 22 de set. de 2018. Às 19 h.

Lück, Heloísa. Liderança em Gestão Escolar, 168 págs., Ed. Vozes, Petrópolis, RJ. 2014. 
NEVES, Ana Paola. Blog - FCE. O Reflexo Da Gestão Escolar Na Qualidade Do

Ensino. Ano de Publicação 2018. Disponível em: http://fce.edu.br/blog/o-reflexo-dagestao-escolar-na-qualidade-do-ensino/. Acesso em: 27 de out. de 2018. Às: 16h e $45 \mathrm{~min}$.

PASCHOALINO, Jussara Bueno de Queiroz. Desafios da Gestão Escolar, 340p. Belo Horizonte: Studium Eficaz. MG, 2017.

PEREIRA, Luzia Alves e VIEIRA, Leociléa Aparecida. Os Desafios Da Escola Pública Paranaense Na Perspectiva Do Professor PDE. O Índice De Desenvolvimento Da Educação Básica (Ideb), Como Norteador Da Qualidade Educacional: Analisando Seus Pressupostos Teóricos. Disponível em: http://www.diaadiaeducacao.pr.gov.br/portals/cadernospde/pdebusca/producoes_pd e/2013/2013_fafipar_ped_artigo_luzia_alves_pereira.pdf. Acesso em: 29 de out. de 2018. Às: $15 \mathrm{~h}$ e $10 \mathrm{~min}$.

Enviado: Fevereiro, 2019.

Aprovado: Julho, 2019. 